\title{
Optimization of Antimicrobial Combined Effect of Organic Acids and Temperature on Foodborne Salmonella and Escherichia coli in Cattle Feed by Response Surface Methodology
}

\author{
Isabel Rodríguez Amado,, Jose Antonio Vázquez, ${ }^{1,2}$ Pablo Fuciños, ${ }^{1,2}$ \\ Jesús Méndez, and Lorenzo Pastrana ${ }^{1}$
}

\begin{abstract}
Despite the importance of feedstuffs and feed ingredients in the food chain, few studies have analyzed the effectiveness of usual methods for the microbial decontamination of feeds. This work aimed to study the combined effect of temperature and organic acids (formic or lactic) on the inactivation of 10 isolates of Salmonella enterica and Escherichia coli obtained from vegetable feed ingredients, including cereals and other processed materials, in cattle feed. A central composite design was used with acid concentrations ranging from 0 to $0.2 \%$ (vol/wt) and temperatures from $50^{\circ} \mathrm{C}$ to $70^{\circ} \mathrm{C}$. Second-order models were obtained to predict the survival inhibitions. The results reported in the present study indicate that temperature affects the survivability more significantly than acid concentration, whose effect was isolate dependent. However, after 2 min of treatment, optimal microbial inhibitions were generally achieved at temperatures above $65^{\circ} \mathrm{C}$, using $0.1 \%$ formic acid or $0.2 \%$ lactic acid for Salmonella isolates and around $0.1 \%$ lactic acid or $0.2 \%$ formic acid for E. coli isolates, respectively. This work provides a set of guidelines helpful to reduce microbial contamination of feeds and highlights the importance of feed-ingredient monitoring to reduce pathogen contamination risk during feed processing.
\end{abstract}

\section{Introduction}

B ACTERIAL CONTAMINATION OF FEEDS is considered a vehicle for the transmission of pathogens, such as Salmonella enterica (Davis et al., 2003) and Escherichia coli, including E. coli O157:H7 (Jones and Richardson, 2004). In fact, contamination with these foodborne pathogens is quite frequent (Davis et al., 2003), feed ingredients being one of the sources of such contamination (Dargatz et al., 2005).

Different approaches have been taken to minimize contamination with pathogenic microorganisms in the farm environment, from preharvest control strategies (Sargeant et al., 2007) to risk assessment of farm management practices (Van Immerseel et al., 2009). Among the wide number of decontamination methods available for feedstuffs, heat treatments are one of the most effective. During animal feed manufacturing, heat treatments occur either at conditioning, and/or during the pelleting process (Hutchison et al., 2007).
Retention times of feed mash depend on the formulation and mass of feed, final temperature, and equipment used (Hutchison et al., 2007). Times of heat treatment from $<1 \mathrm{~min}$ at $71.1^{\circ} \mathrm{C}$ (Matlho et al., 1997) to $3.5-4.0 \mathrm{~min}$ at $78^{\circ} \mathrm{C}-80^{\circ} \mathrm{C}$ (Blank et al., 1996) have been reported for decontaminating poultry feed.

Although heat treatments are usually effective, combinations of time/temperature for commercial feed production can be insufficient to eliminate high numbers of microorganisms (Maciorowski et al., 2006; Hutchison et al., 2007). Since feeds are nonsterile (Jones and Richardson, 2004) and sensitive to postprocessing recontamination (Maciorowski et al., 2006), usually more than one strategy is used to prevent microbial growth in feedstuffs.

Organic acids have been traditionally used as preservatives due to their antimicrobial activity. Although their antibacterial mechanism is not fully understood, it has been extensively studied (Giotis et al., 2007) and appears to be due primarily to

\footnotetext{
${ }^{1}$ Departamento de Química Analítica y Alimentaria, Facultad de Ciencias de Ourense, Universidad de Vigo, Ourense, Spain.

${ }^{2}$ Grupo de Reciclado y Valorización de Materiales Residuales (REVAL), Instituto de Investigaciones Marinas-IIM (CSIC), Vigo, Pontevedra, Spain.

${ }^{3}$ Cooperativas Orensanas Sociedad Cooperativa Ltda (COREN), Polígono San Ciprián de Viñas, Ourense, Spain.
} 
the undissociated acid form interfering with cell metabolism (Cherrington et al., 1990). Among organic acids, short-chain fatty acids such as formic (Al-Natour and Alshawabkeh, 2005) and propionic (Ha et al., 1998) have been investigated as bactericidals in feed and feed ingredients. The antimicrobial effects of organic acids can occur during feed processing, prevent recontamination during storage (Wales et al., 2010), or exert their antimicrobial activity in the animal gastrointestinal tract (Cherrington et al., 1991).

The objective of this work was to study the combined effect of temperature and acid concentration on microbial inactivation in cattle feed, using response surface methodology. We studied the behavior of 10 isolates of Salmonella and E. coli from different vegetable feed ingredients in acidified feeds with formic or lactic acid, at temperatures between $50^{\circ} \mathrm{C}$ and $70^{\circ} \mathrm{C}$.

\section{Materials and Methods}

\section{Bacterial strains}

Bacteria were isolated from vegetable feed ingredients: wheat bran (slSAL-1, ecSAL-3), corn (slMAZ-1, ecMAZ-4), soybean meals $47 \%$ (slSJ7-1, ecSJ7-1, ecSJ4-2), cottonseed (slALG$1)$, corn dry distillers grains with solubles (DDGS) (slDDM-1), and barley $(e c C E B-1)$. Detection and isolation were performed using the ISO methods for Salmonella (ISO 6579: 2002) and E. coli (ISO 4831:2006 and 4832:2006) detection in food and animal feed. Biochemical confirmative tests were performed following preliminary identification of colony morphology on selective media. Isolates were preserved as frozen stocks at $-80^{\circ} \mathrm{C}$ in Tryptic Soy Broth (TSB; Cultimed Panreac Química S.A., Barcelona, Spain) containing 30\% (vol/vol) of glycerol, and propagated twice before use. Cultures were grown in Erlenmeyer flasks containing $50 \mathrm{~mL}$ of $\mathrm{TSB}$ at $37^{\circ} \mathrm{C}$ for $12 \mathrm{~h}$.

\section{Preparation of acidified contaminated feed}

An acid-free pelleted cattle feed (Table 1) supplied by a local commercial manufacturer (COREN S.C.L., Ourense, Spain) was utilized in this work. On arrival, each feed batch

Table 1. Percentage Composition of the Experimental Feed Used in This Study

\begin{tabular}{lrlr}
\hline Composition & $\%$ & \multicolumn{2}{c}{ Calculated nutrient content } \\
\hline Soybean & 20.50 Total protein (\%) & 18.50 \\
Corn & 14.50 Total cellulose (\%) & 8.80 \\
Wheat lees DDS & 15.00 Ash (\%) & 7.30 \\
Corn gluten & 17.70 Available phosphorus (\%) & 4.80 \\
Cassava & 10.00 Crude fat & 0.80 \\
Soybean hull & 7.00 & \\
Barley & 6.50 & \\
Molasses & 3.50 & \\
Vegetal fat & 1.80 & \\
Calcium carbonate & 1.23 & \\
Sodium chloride & 0.81 & \\
Calcium phosphate & 0.78 & \\
Fatty acids & 0.50 & \\
Vitamin premix ${ }^{\text {a }}$ & 0.18 &
\end{tabular}

a Premix contains per kg: vitamin A $10^{4} \mathrm{IU}$, vitamin D3 $2 \times 10^{3} \mathrm{IU}$, and vitamin E $10 \mathrm{mg}$.

DDS, dry distillers solubles. was assessed for both Salmonella and E. coli using the ISO methods indicated above that confirmed no Salmonella nor E. coli were present in any of the batches analyzed. The commercial feed utilized (Table 1) was milled using a laboratory mill (IKA-Werke GmbH \& Co. KG, Staufen, Germany) with a 3-mm sieve and sterilized by autoclaving $\left(105^{\circ} \mathrm{C}\right.$, $5 \mathrm{~min})$. Formic or lactic acid solutions were sprayed in a $1 \%$ ( $\mathrm{vol} / \mathrm{wt}$ ) to achieve concentrations from 0.02 to $0.2 \%$ (vol/ $\mathrm{wt}$ ) (BASF, Ludwigshafen, Germany). Cultures were centrifuged $\left(13,000 \times g, 10 \mathrm{~min}, 4^{\circ} \mathrm{C}\right)$, and cells were resuspended in phosphate-buffered saline (PBS) and added at $2 \%$ (vol/wt) to the feed. The number of cells in the contaminated feed was determined before heat treatment and was of $1 \times 10^{5}$ to $1 \times 10^{6}$ $\mathrm{CFU} / \mathrm{g}$ for all assayed conditions and isolates. Both acid solutions and cultures were sprayed and then agitated endover-end in a 1.5-L plastic beaker for $4 \mathrm{~min}$, as previously optimized. Control samples with identical moisture levels $(3 \%)$ were used to monitor the time required to achieve the selected temperatures.

\section{Thermal inactivation}

Disks utilized in this work were similar to those described by Jin et al. (2008). However, in this article, thermal-death-time disks were reusable devices with a cavity of $4.5 \mathrm{~mm}$ height (i.e., $28 \%$ thicker than those utilized in the present work [3 mm]). Furthermore, our single-use disks consisted of a flat rubber o-ring completely sealed by two layers of 0.015-mmthick aluminum, whereas those of Jin et al. (2008) were approximately $2 \mathrm{~mm}$ thick. Under these conditions, heat transfer is highly favored, being the time required to achieve the selected temperatures of $26 \mathrm{~s}$ on average. Devices were filled with $1 \mathrm{~g}$ of feed and submerged in a water bath at temperatures shown in Table 2, including a noninoculated sample to monitor each assayed temperature. After a 2-min treatment, triplicate samples were removed, cooled, and sanitized with sodium hypochlorite. After rinsing, the feed was homogenized with $10 \mathrm{~mL}$ of PBS to obtain the count suspension $\left(S_{c}\right)$. Serial dilutions were made from $S_{c}, 0.1 \mathrm{~mL}$ plated in duplicate in tryptic soy agar, and incubated at $37^{\circ} \mathrm{C}$ for $48 \mathrm{~h}$. Enumeration was also performed before heat treatment, and the inhibition of survival was calculated as follows:

$$
I=\frac{\left(N_{0}-N_{t}\right)}{N_{0}} \times 100
$$

where $I$ is the bacterial inhibition (\% of CFU/g), $N_{0}$ is the initial number of cells (CFU/g), and $N_{t}$ is the number of survivors (CFU/g) after the heat treatment.

TABle 2. Experimental Domain ANd Codification OF INDEPENDENT VARIABLES IN THE ORTHOGONAL Second-Order Design

\begin{tabular}{lcc}
\hline \multirow{2}{*}{ Coded values } & $\begin{array}{c}\text { Natural values of temperature }(T) \\
\text { and organic acid concentration }(A)\end{array}$ \\
\cline { 2 - 3 }-1.267 & $T\left({ }^{\circ} \mathrm{C}\right)$ & $A(\%)$ \\
-1 & 50.1 & 0 \\
0 & 52.2 & 0.02 \\
+1 & 60.1 & 0.10 \\
+1.267 & 68.0 & 0.18 \\
\hline
\end{tabular}




\section{Experimental design and statistical analysis}

Bacterial inhibition was studied using a second-order central composite orthogonal design $(\alpha=1.267)$, with quintuple replication in the center of the factorial design, but not in other points of the experimental domain (Akhnazarova and Kafarov, 1982; Box et al., 2005). The range of independent variables, temperature $(T)$, and acid concentration $(A)$ is shown in Table 2.

From the data, empirical equations were obtained describing the significant parameters in relation to temperature and acid concentration. The general form of the second-order polynomial equation is:

$$
I=b_{0}+\sum_{i=1}^{2} b_{i} x_{i}+\sum_{i, j=1(i \neq j)}^{2} b_{i j} x_{i} x_{j}+\sum_{i=1}^{2} b_{i i} x_{i}^{2}
$$

where $I$ is the bacterial inhibition (\% of CFU/g), $b_{0}$ is the constant coefficient, $b_{i}$ is the linear effect coefficient, $b_{i j}$ is the interaction effect coefficient, $b_{i i}$ are the squared effect coefficients, and $x_{i}$ and $x_{j}$ represent the independent variables ( $\mathrm{T}$ and $\mathrm{A}$ ).

The goodness-of-fit was established as the adjusted determination coefficient, the statistical significance of the coefficients verified by means of the Student $t$-test $(\alpha=0.05)$, and the model consistency by the Fisher $F$ test $(\alpha=0.05)$ using the following mean-squares ratios:

The model is acceptable if

F1 $=$ Model $/$ Total error

$\mathrm{F} 2=($ Model + Lack of fitting $) /$ Model

F3 $=$ Total error/Experimental error

F4 = Lack of fitting/Experimental error

$\mathrm{F} 1 \geq F_{\text {den }}^{\text {num }}$

$\mathrm{F} 2 \leq F_{\text {den }}^{\text {num }}$

$\mathrm{F} 3 \leq F_{\text {den }}^{\text {num }}$

$\mathrm{F} 4 \leq \mathrm{F}_{\text {den }}^{\text {num }}$

Deriving the equations with respect to $\mathrm{T}$ and $\mathrm{A}$ and equaling the expression to zero can calculate maximum values for each variable $\left(T_{m}\right.$ and $\left.A_{m}\right)$, while optimum inhibition $\left(I_{m}\right)$ is calculated replacing $T_{m}$ and $A_{m}$.

\section{Results}

A central composite orthogonal design was chosen to optimize both variables. The upper limits of temperature and acid concentration were selected not exceeding the usual values of commercial feed nor affecting dry matter intake by the animals. The experimental domain $(-1.267,1.267)$ was $0-0.2 \%$ (vol $/ \mathrm{wt}$ ) of acid and $50^{\circ} \mathrm{C}-70^{\circ} \mathrm{C}$ (Table 2). Considering a possible synergistic effect between variables, their optimum levels would provide a set of safety values ensuring a feasible treatment to be implemented in the food industry. The time of heat treatment was fixed to $2 \mathrm{~min}$, which has been reported as enough to achieve a significant reduction in the feed microbial population (Matlho et al., 1997; Hutchison et al., 2007).

\section{Combined effect of formic acid and temperature}

Bacterial inhibition was extremely isolate-dependent. Nonetheless, four patterns of behavior could be defined (Table 3 and Fig. 1):

1. Both variables showed a negative quadratic coefficient.

2. Only temperature revealed a quadratic effect with negative coefficient.

3. Only acid concentration had a negative quadratic term.

4. Only temperature showed a significant quadratic effect with positive coefficient.

Behavior 1. This was the major response, since half of the assayed isolates (slMAZ-1, slSJ7-1, slALG-1, ecCEB-1, and ecMAZ-4) showed this behavior. Empirical models were characterized by negative coefficients for quadratic variables, suggesting a saturation of the response at high values of $\mathrm{T}$ and A, or the existence of optimum values within the experimental domain. In fact, predicted temperatures for optimal antimicrobial effects were located close to the maximum levels assayed, being always higher than $65^{\circ} \mathrm{C}$. By contrast, optimal formic concentrations were generally observed at intermediate concentrations of acid (Fig. 1a).

Except for slSJ7-1, empirical equations had interaction coefficients, so a different formic acid effect was observed depending on treatment temperature. However, the interaction sign was isolate dependent, obtaining (when this term was positive) maximal inhibition of one variable for maximum value of the other (Fig. 1a). This interaction was highest for ecMAZ-4, since the coefficient (TA) was close to those of the

Table 3. Empirical Models Describing the Combined Effect of Temperature $(T)$ and Formic Acid $(A)$

Concentration on the Inhibition of Survival $(I)$ of Different Bacterial Isolates from Vegetable Feed Ingredients. Optimal Values of Temperature $\left(T_{M}\right)$ and Formic Acid $\left(A_{M}\right)$ And Maximum of Inhibition $\left(I_{M}\right)$ Are Also Shown

\begin{tabular}{|c|c|c|c|c|c|}
\hline Behavior & Isolate & Second-order equation & $\mathrm{T}_{\mathrm{m}}\left({ }^{\circ} \mathrm{C}\right)$ & $\mathrm{A}_{\mathrm{m}}(\%)$ & $\mathrm{I}_{\mathrm{m}}(\%)$ \\
\hline 1 & $\begin{array}{l}\text { slMAZ-1 } \\
\text { slALG-1 } \\
\text { ecMAZ-4 } \\
\text { slSJ7-1 } \\
\text { ecCEB-1 }\end{array}$ & $\begin{array}{l}I(\%)=99.21+2.63 T+1.39 A-1.12 \mathrm{~T} A-1.35 T^{2}-1.04 A^{2} \\
I(\%)=99.17+9.35 T-2.39 A+2.08 T A-6.52 T^{2}-2.56 A^{2} \\
I(\%)=99.27+3.83 T-1.36 A+2.64 T A-2.45 T^{2}-0.87 A^{2} \\
I(\%)=95.49+7.24 T-1.82 T^{2}-2.21 A^{2} \\
I(\%)=99.37+0.43 T+0.31 T A-0.27 T^{2}-0.35 A^{2}\end{array}$ & $\begin{array}{l}67.2 \\
65.7 \\
75.7 \\
75.8 \\
68.5\end{array}$ & $\begin{array}{l}0.115 \\
0.098 \\
0.267 \\
0.100 \\
0.138\end{array}$ & $\begin{array}{r}100.5 \\
102.5 \\
101.6 \\
102.7 \\
99.6\end{array}$ \\
\hline 2 & $\begin{array}{l}\text { slDDM-1 } \\
\text { ecSAL-3 }\end{array}$ & $\begin{array}{l}I(\%)=96.63+5.21 T-2.32 T^{2} \\
I(\%)=97.96+7.28 T+3.32 A-3.87 T A-4.38 T^{2}\end{array}$ & $\begin{array}{l}69.0 \\
66.9\end{array}$ & $\begin{array}{l}0-0.2 \\
0.095\end{array}$ & $\begin{array}{r}99.5 \\
101.0^{\mathrm{a}}\end{array}$ \\
\hline 3 & slSAL-1 & $I(\%)=87.36+13.26 T-6.67 A^{2}$ & $50-70$ & 0.100 & 104.2 \\
\hline 4 & $\begin{array}{l}\text { ecSJ7-2 } \\
\text { ecSJ4-2 }\end{array}$ & $\begin{array}{l}I(\%)=92.07+3.06 T+2.23 A+2.45 T^{2} \\
I(\%)=91.14+4.09 T+4.09 A-5.27 T A+3.60 T^{2}\end{array}$ & $\begin{array}{l}70.1 \\
70.1 \\
50.1\end{array}$ & $\begin{array}{r}0.2 \\
0 \\
0.2\end{array}$ & $\begin{array}{l}102.7^{\mathrm{a}} \\
105.3^{\mathrm{a}} \\
105.3^{\mathrm{a}}\end{array}$ \\
\hline
\end{tabular}

a Response surface presents a saddle point. An absolute maximum cannot be calculated, so optimal values correspond to local maxima within the experimental domain (see text for more details). 
a I (\%)

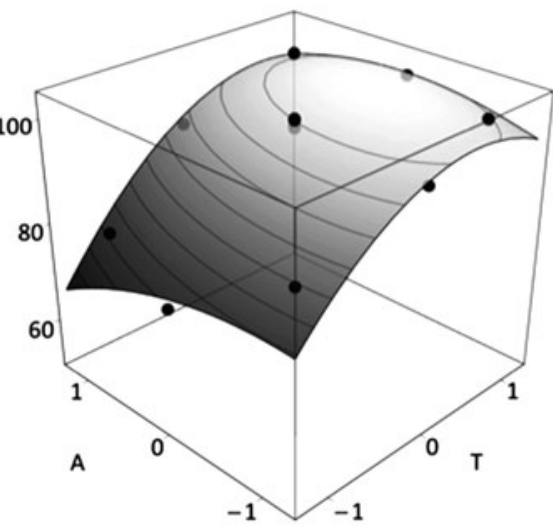

C

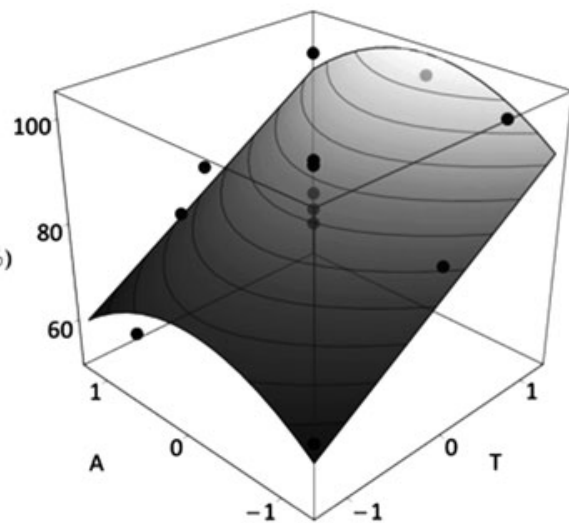

b
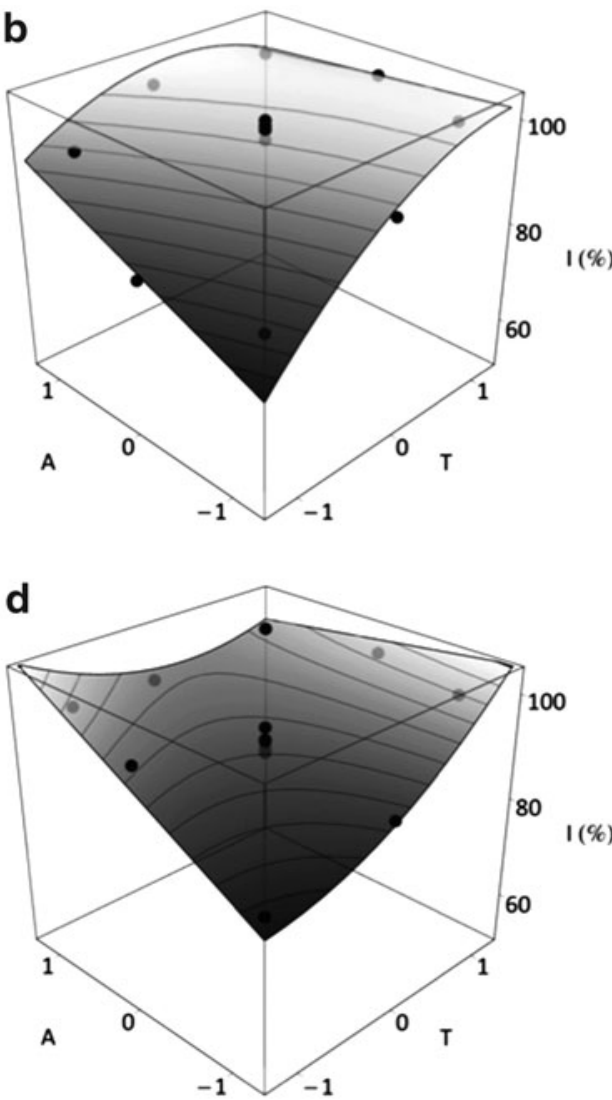

FIG. 1. Selection of response surfaces for bacterial inhibition (I) as a function of formic acid $(A)$ and temperature $(T)$, according to the equations described in Table 3. a: slALG-1, b: ecSAl-3, c: $s l S A L-1$, and d: ecSJ4-2 isolates. Independent variables are expressed in codified values. Symbols $(\bullet)$ indicate experimental data.

linear variables $T$ and $A$. On the other hand, the negative interaction in slMAZ-1 indicates that at high temperature an increase in formic concentration does not produce remarkable effects on the response, whereas at low temperature a clear inhibitory effect is revealed. The lack of interaction term generates a symmetrical response surface where each variable has identical effect for high and low levels of the other one.

Behavior 2. The behavior of isolates slDDM-1 and ecSAL-3 is characterized by empirical models including a quadratic term for temperature and a linear dependence of inhibition with formic acid concentration. Equation obtained for slDDM-1 isolate showed that formic acid had no effect, although the response surface of ecSAL-3 revealed a clear inhibitory effect of formic acid at low temperatures (Fig. 1b).

Behavior 3. The response of $s I S A L-1$ described a positive linear effect of $T$ and a negative quadratic effect of $A$ (Fig. 1c). The absence of interaction term leads to rising ridge, a convex surface with a line of maxima at $0.1 \% A$ but without an absolute maximum response within the experimental domain. However, in all cases the inhibition increases with temperature, reaching a $100 \%$ inhibition at $0.1 \% \mathrm{~A}$ and $70.1^{\circ} \mathrm{C}$.

Behavior 4. Two E. coli isolates from soybean meal (ecSJ7-2 and ecSJ4-2) showed a different experimental tendency. Although empirical equations included quadratic terms for temperature, they had positive sign leading to slightly concave response surfaces (Fig. 1d). In ecSJ7-2, the concavity observed by effect of $T$ and positive influence of $A$, produced a softly shift of the optimal values of both variables towards their maximum level $\left(100 \%\right.$ inhibition at $70.1^{\circ} \mathrm{C}$ and $0.2 \% \mathrm{~A})$. At any level of A, lower inhibitions were observed at $55.2^{\circ} \mathrm{C}$, with a minimum at $55.2^{\circ} \mathrm{C}$ and $0 \% \mathrm{~A}$. The response surface model for ecSJ4-2 presents a saddle point, meaning an absolute maximum response cannot be obtained within the experimental domain. However, a negative interaction term and positive linear coefficients for $T$ and $A$ cause a response increasing with both $\mathrm{T}$ and $\mathrm{A}$. Maximum inhibitions were obtained in the response surface limits $\left(T_{m}=70.1^{\circ} \mathrm{C}, A_{m}=0 \%\right)$ and $\left(T_{m}=50.1^{\circ} \mathrm{C}, A_{m}=0.2 \%\right)$. From a practical viewpoint, these results indicate that similar levels of inhibition could be obtained when feed is only treated by heat or acid conditions.

\section{Combined effect of lactic acid and temperature}

Less variability was observed when lactic acid was used as antimicrobial agent, leading to different behaviors according to the three mathematical models (Table 4 and Fig. 2):

1. Both variables had second-order terms.

2. Only the temperature showed a quadratic coefficient.

3. Equation without quadratic terms.

Behavior 1. The major behavior observed included quadratic terms for both variables, although the sign of the 
Table 4. Empirical Models Describing the Combined Effect of Temperature $(T)$ and Lactic Acid $(A)$

Concentration on the Inhibition of Survival ( $I$ ) of Different Bacterial Isolates from Vegetable Feed Ingredients. Optimal Values of Temperature (TM) and Formic Acid $(A M)$ And Maximum of Inhibition (IM) Are Also Shown

\begin{tabular}{|c|c|c|c|c|c|}
\hline Behaviour & Isolate & Second order equation & $T_{m}\left({ }^{\circ} \mathrm{C}\right)$ & $A_{m}(\%)$ & $I_{m}(\%)$ \\
\hline 1 & $\begin{array}{l}\text { slDDM-1 } \\
\text { slALG-1 } \\
\text { ecCEB-1 } \\
\text { ecMAZ-4 } \\
\text { ecSJ7-2 } \\
\text { slSAL-1 } \\
\text { ecSAL-3 }\end{array}$ & $\begin{array}{l}I(\%)=99.37+6.37 T-2.48 A+5.01 T A-4.02 T^{2}-2.09 A^{2} \\
I(\%)=99.26+6.90 T-2.40 A+5.05 T A-4.56 T^{2}-1.80 A^{2} \\
I(\%)=99.50+7.88 T-0.95 A+2.54 T A-6.31 T^{2}-0.94 A^{2} \\
I(\%)=99.56+5.82 T-1.67 A+3.17 T A-4.36 T^{2}-1.02 A^{2} \\
I(\%)=97.99+6.71 T+7.37 A-5.68 T A-1.46 T^{2}-6.65 A^{2} \\
I(\%)=95.94+8.04 T-1.55 A-4.59 T^{2}+0.89 A^{2} \\
I(\%)=98.50+3.92 T-3.54 T^{2}+2.13 A^{2}\end{array}$ & $\begin{array}{r}73.3 \\
73.9 \\
65.8 \\
66.8 \\
116.9 \\
67.0 \\
64.5\end{array}$ & $\begin{array}{r}0.213 \\
0.242 \\
0.137 \\
0.140 \\
-0.102 \\
0.170 \\
0.100\end{array}$ & $\begin{array}{r}102.9 \\
103.1 \\
102.1 \\
101.6 \\
112.9^{\mathrm{a}} \\
98.8^{\mathrm{b}} \\
99.6^{\mathrm{b}}\end{array}$ \\
\hline 2 & $\begin{array}{l}\text { slMAZ-1 } \\
\text { slSJ7-1 }\end{array}$ & $\begin{array}{l}I(\%)=97.87+4.86 T-2.79 T^{2} \\
I(\%)=96.46+7.69 T-3.76 T^{2}\end{array}$ & $\begin{array}{l}67.0 \\
68.2\end{array}$ & $\begin{array}{l}0-0.2 \\
0-0.2\end{array}$ & $\begin{array}{l}100.0 \\
100.4\end{array}$ \\
\hline 3 & ecSJ4-2 & $I(\%)=98.38-1.15 T+1.08 T A$ & 60.1 & 0.185 & 98.4 \\
\hline
\end{tabular}

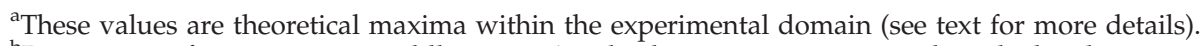

${ }^{\mathrm{b}}$ Response surface presents a saddle point. An absolute maximum cannot be calculated, so optimal values correspond to local maxima within the experimental domain (see text for more details).

quadratic coefficients was not always negative. Salmonella (slALG-1 and slDDM-1) and E. coli isolates (ecCEB-1, ecSJ7-2 and ecMAZ-4) showed inhibition surfaces (Fig. 2a and b) similar to those of formic acid, but with a higher inhibitory effect (Fig. 2a). For Salmonella isolates, the maxima of both variables were predicted out of the experimental domain $\left(T_{m}>73^{\circ} \mathrm{C}\right.$ and $\left.A_{m}>0.21 \%\right)$, although the combinations $\mathrm{T}=70.1^{\circ} \mathrm{C}$ and $\mathrm{A}=0.17 \%$ for slDDM-1, and $\mathrm{T}=70.1^{\circ} \mathrm{C}$ and

a

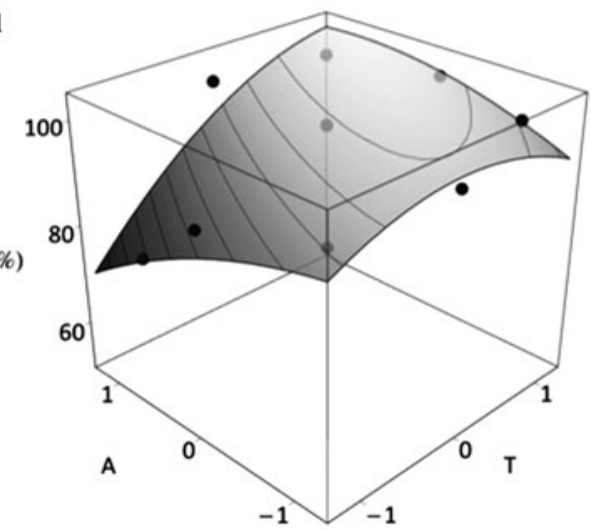

C

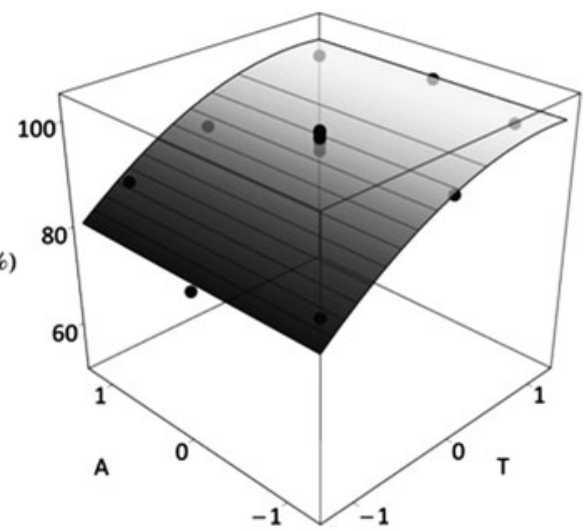

$\mathrm{A}=0.19 \%$ for slALG-1 provided inhibitions only $0.2 \%$ lower than the maxima. However, clear optima were calculated for E. coli isolates: $65.8^{\circ} \mathrm{C}$ and $0.137 \%(e c C E B-1)$ and $66.8^{\circ} \mathrm{C}$ and $0.14 \%$ (ecMAZ-4).

The negative interaction term and the difference between linear and quadratic coefficients in ecSJ7-2 resulted in an $I_{m}(112.9 \%)$ at high temperature $\left(116.9^{\circ} \mathrm{C}\right)$. Nonetheless, this result should be considered as a mathematical artefact
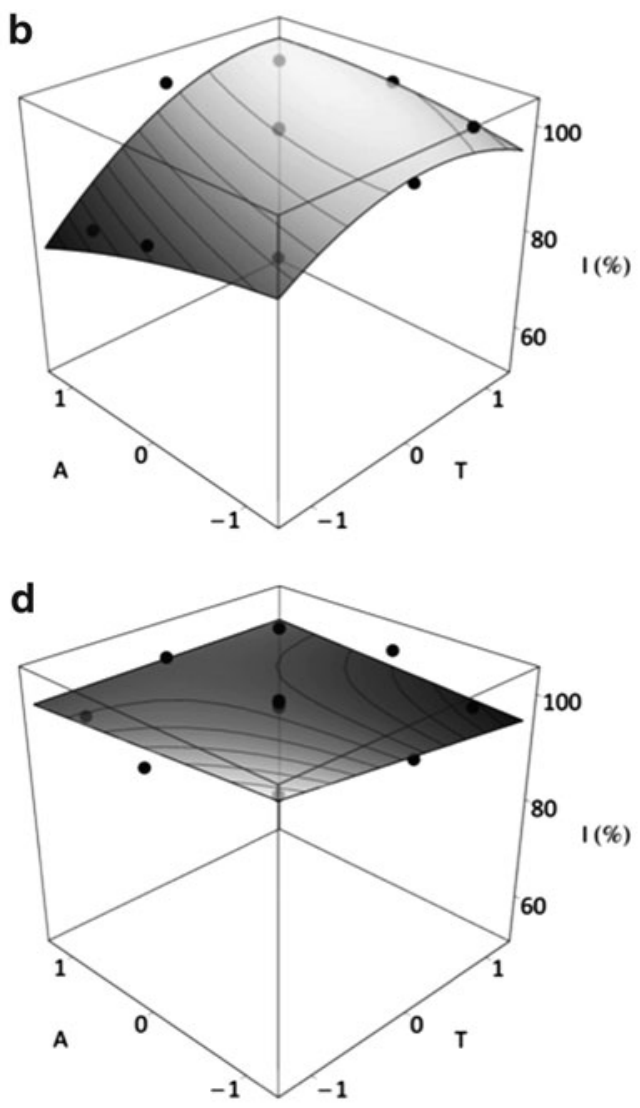

FIG. 2. Selection of response surfaces for bacterial inhibition (I) as a function of lactic acid $(A)$ and temperature $(T)$, according to the equations described in Table 4. a: slDDM-1, b: ecMAZ-4, c: slSJ7-1, and d: ecSJ4-2 isolates. Independent variables are expressed in codified values. Symbols $(\bullet)$ indicate experimental data. 
since the maximum acid concentration value was negative $\left(A_{m}=-0.102 \%\right)$.

Equations for wheat bran isolates (ecSAL-3 and slSAL-1) had positive quadratic terms for lactic acid. In $s I S A L-1$, the effect of $T$ was higher than $A$, whereas for ecSAL-3 both contributions were similar. Antimicrobial optimal conditions were $67^{\circ} \mathrm{C}, 0.17 \%$ and $64.5^{\circ} \mathrm{C}, 0.1 \%$ for $s l S A L-1$ and $e c S A L-3$, respectively.

Behavior 2. This group included two isolates (slMAZ-1 and slSJ7-1) in which only the temperature had influence on survival inhibition. For both bacteria, there was an increased inhibition with increasing temperature until a temperature optimum: $67^{\circ} \mathrm{C}$ for $s l M A Z-1$ and $68.2^{\circ} \mathrm{C}$ for slSJ7-1 (Fig. 2c).

Behavior 3. Empirical equation for ecSJ4-2 did not present second-order coefficients for $T$ and $A$ nor a linear term for $A$, which is only present in a positive interaction term (Fig. 2d). In this case, the low value of the coefficients determined minor effects on the response, with inhibitions near $100 \%$ within the entire experimental domain.

\section{Discussion}

Although microbial inactivation in cattle feed has been scarcely investigated, some studies have analyzed bacterial survival either under thermal treatments (Blank et al., 1996; Hutchison et al., 2007) or acidic conditions (Ha et al., 1998; AlNatour and Alshawabkeh, 2005). Nevertheless, some reports suggest that heat treatment alone may be insufficient to eliminate high numbers of microorganisms (Maciorowski et al., 2006; Hutchison et al., 2007) or that under certain circumstances, organic acids can promote microbial growth in feeds (Lynn et al., 1998). Since acidifiers are usually added to raw materials and finished feeds, it is a key factor to know whether they ensure significant reductions in the microbial load at typical feed-manufacturing temperatures. The most efficient methodology to evaluate the combined effect of two factors at the same time is the use of response surface methodology (RSM), allowing the prediction of optimal values of the independent variables and minimizing experiments.

In this work, a central composite orthogonal second-order design (Akhnazarova and Kafarov, 1982; Box et al., 2005) was used to study the combined effect of temperature and organic acids on the inactivation of foodborne isolates in cattle feed. The obtained models can be considered good predictors for the experimental data, since the equations are consistent according to the values of mean-squares ratios $\left(F_{1}, F_{2}, F_{3}\right.$, and $\left.F_{4}\right)$. The adjusted determination coefficients $\left(R_{a d j}^{2}\right)$ calculated were always higher than 0.8 , meaning the second-order equations accounted more than $80 \%$ of the response variability. All equations showed independent terms $\left(b_{0}\right)>87 \%$, which might be related to osmotic shock caused by the low feed water activity (Mossel and Koopman, 1965). Nonetheless, in general the increase of each variable led to linear or parabolic inhibitions, obtaining in some cases clear optima within the experimental conditions. For each isolate, combinations of $\mathrm{T}$ and A providing inhibitions close to $99 \%$ were found. Although in some cases maximal survival inhibitions $\left(I_{m}\right)>100 \%$ were obtained, they should be considered calculation artefacts and assumed as complete inhibitions under these conditions.
According to the response surfaces obtained, bacterial inhibition was primarily affected by heat. These results reveal that when using acidification as the sole feed treatment, longer storage times are needed to achieve significant reductions in the microbial load. In fact, Al-Natour and Alshawabkeh (2005) reported a 2 log-units decrease of Salmonella enterica Gallinarum in broiler feed treated with formic acid $(0.5 \%-$ $1.5 \%$ ) after 7 days. Even minor reductions ( $<1$ log-unit) in Salmonella Typhimurium counts were observed in soybean meal-based poultry mash treated with $1 \%$ buffered propionic acid after the same storage time (Ha et al., 1998).

Despite heat being the variable that most influenced bacterial inhibition, significant interactions were generally observed, allowing the use of lower temperature and antimicrobial agent than when these treatments are used alone. Nevertheless, synergistic interactions between heat and antimicrobial acids did not always occur, with negative interaction terms primarily in the presence of formic acid. These results, leading to lower inhibitions than expected at high temperatures and acid concentrations, could be due to the high volatility of formic acid (Al-Natour and Alshawabkeh, 2005) or to the buffering capacity of some components in the feed matrix (Pursiainen and Tuori, 2008). Similarly, Matlho et al. (1997) did not find interactions between heating time and acid concentration when evaluating the reduction of Salmonella Enteritidis in poultry feed treated with propionic acid $(0 \%-0.2 \%)$ at $71.1^{\circ} \mathrm{C}$.

Formic acid has greater antimicrobial activity against enterobacteria compared to lactic acid (Ostling and Lindgren, 1993). Its low molecular weight and high hydrophobicity might favor its ability to diffuse freely across the cell membrane, interfering with intracellular $\mathrm{pH}$ (Cherrington et al., 1991). By contrast, our results showed that lactic acid was better for the decontamination of cattle feed inoculated with E. coli isolates, since milder conditions were needed to achieve similar inhibitions than using formic acid.

Since the effect of both variables on the inhibition depended largely on the type of acid and isolate, it was not possible to generalize a combination of variables achieving a complete survival inhibition of all isolates. However, process parameters were effectively optimized using RSM, obtaining maximal survival inhibitions (>98\%) at temperatures above $65^{\circ} \mathrm{C}$ in cattle feed acidified with $0.1 \%$ formic for Salmonella isolates and $0.1 \%$ lactic acid for $E$. coli isolates after 2 min of treatment. Then, for the same temperature and treatment time, nearly twice the concentration of lactic acid for Salmonella and formic acid for E. coli were required to achieve similar inhibitions. Under these conditions, population declines between 2 and 4 log-units are reached. These results are comparable to those obtained by Matlho et al. (1997), who reported an approximately 10,000-fold reduction in living Salmonella after 80-s heating at $71.1^{\circ} \mathrm{C}$ in poultry feed acidified with $0.2 \%$ propionic acid.

\section{Conclusions}

Our results provide a set of guidelines useful to reduce contamination with foodborne pathogens during feed processing, highlighting the importance of ingredient monitoring during animal feed production. We report optimal inhibitions at temperatures above $65^{\circ} \mathrm{C}$ with $0.1 \%$ formic acid or $0.2 \%$ lactic acid for Salmonella isolates and around $0.1 \%$ lactic acid 
or $0.2 \%$ formic acid for E. coli isolates, respectively. Although these treatments represent significant reductions of target microorganisms $(>98 \%)$, they should be validated under commercial production conditions.

\section{Acknowledgments}

We thank COREN, S.C.L. for their collaboration in the elaboration of this work. This research was financially supported by the Xunta de Galicia, Spain (project PGIDIT03TAL07E). Isabel Rodríguez Amado was funded by a PhD fellowship from the Plan Galego de Investigación, Desenvolvemento e Innovación Tecnolóxica-Incite (2006-2010) (Xunta de Galicia).

\section{Disclosure Statement}

No competing financial interests exist.

\section{References}

Akhnazarova SL, Kafarov VV. Experiment Optimization in Chemistry and Chemical Engineering. Moscow: MIR Publishers, 1982.

Al-Natour MQ, Alshawabkeh KM. Using varying levels of formic acid to limit growth of Salmonella gallinarum in contaminated broiler feed. Asian Austral J Anim Sci 2005;18:390-395.

Blank G, Savoie S, Campbell LD. Microbiological decontamination of poultry feed: Evaluation of steam conditioners. J Sci Food Agric 1996;72:299-305.

Box GEP, Hunter JS, Hunter WG. Statistics for Experimenters: Design, Innovation, and Discovery. Hoboken, NJ: John Wiley \& Sons Inc., 2005.

Cherrington CA, Hinton M, Chopra I. Effect of short-chain organic acids on macromolecular synthesis in Escherichia coli. J Bacteriol 1990;68:69-74.

Cherrington CA, Hinton M, Mead GC, Chopra I. Organic acids: Chemistry, antibacterial activity and practical applications. Adv Microb Physiol 1991;32:87-108.

Dargatz DA, Strohmeyer RA, Morley PS, Hyatt DR, Salman MD. Characterization of Escherichia coli and Salmonella enterica from cattle feed ingredients. Foodborne Pathog Dis 2005;2:341-347.

Davis MA, Hancock DD, Rice DH, Call DR, DiGiacomo R, Samadpour M, Besser TE. Feedstuffs as a vehicle of cattle exposure to Escherichia coli O157:H7 and Salmonella enterica. Vet Microbiol 2003;95:199-210.

Giotis ES, McDowell DA, Blair IS, Wilkinson BJ. Role of branched-chain fatty acids in $\mathrm{pH}$ stress tolerance in Listeria monocytogenes. Appl Environ Microbiol 2007;73:997-1001.

Ha S, Maciorowski K, Kwona Y, Jones F, Ricke S. Survivability of indigenous microflora and a Salmonella typhimurium marker strain in poultry mash treated with buffered propionic acid. Anim Feed Sci Technol 1998;75:145-155.

Hutchison ML, Thomas DJI, Avery SM. Thermal death of Escherichia coli O157:H7 in cattle feeds. Lett Appl Microbiol 2007;44:357-363.

Jin T, Zhang H, Boyd G, Tang J. Thermal resistance of Salmonella enteritidis and Escherichia coli $\mathrm{K} 12$ in liquid egg determined by thermal-death-time disks. J Food Eng 2008;84:608-614.

Jones FT, Richardson KE. Salmonella in commercially manufactured feeds. Poult Sci 2004;83:384-391.

Lynn TV, Hancock DD, Besser TE, Harrison JH, Rice D, Stewart NT, Rowan LL. The occurrence and replication of Escherichia coli in cattle feeds. J Dairy Sci 1998;81:1102-1108.

Maciorowski KG, Herrera P, Jones F, Pillai SD, Ricke SC. Cultural and immunological detection methods for Salmonella spp. in animal feeds: A review. Vet Res Commun 2006;30: 127-137.

Matlho G, Himathongkham S, Riemann H, Kass P. Destruction of Salmonella enteritidis in poultry feed by combination of heat and propionic acid. Avian Dis 1997;41:58-61.

Mossel D, Koopman M. Losses in viable cells of Salmonellae upon inoculation into dry animal feeds of various types. Poultry Sci 1965;44:890-892.

Ostling CE, Lindgren SE. Inhibition of enterobacteria and Listeria growth by lactic, acetic and formic acids. J Appl Bacteriol 1993;75:18-24.

Pursiainen P, Tuori M. Effect of ensiling field bean, field pea and common vetch in different proportions with whole-crop wheat using formic acid or an inoculant on fermentation characteristics. Grass Forage Sci 2008;63:60-78.

Sargeant JM, Amezcua MR, Rajic A, Waddell L. Pre-harvest interventions to reduce the shedding of E. coli $\mathrm{O} 157$ in the faeces of weaned domestic ruminants: A systematic review. Zoonoses Public Health 2007;54:260-277.

Van Immerseel F, De Zutter L, Houf K, Pasmans F, Haesebrouck F, Ducatelle R. Strategies to control Salmonella in the broiler production chain. World Poult Sci J 2009;65:367-391.

Wales AD, Allen VM, Davies RH. Chemical treatment of animal feed and water for the control of Salmonella. Foodborne Pathog Dis 2010;7:3-15.

Address correspondence to: Isabel Rodríguez Amado, PhD

Departamento de Química Analítica y Alimentaria Facultad de Ciencias de Ourense Universidad de Vigo As Lagoas s/n Ourense, Spain

E-mail: sabelara@uvigo.es 